LETTER

If you have a burning desire to respond to a paper published in JECH, why not make use of our "rapid response" option?

Log on to our web site (www.jech.com), find the paper that interests you, and send your response via email by clicking on the "eletters" option in the box at the top right hand corner.

Providing it isn't libellous or obscene, it will be posted within seven days. You can retrieve it by clicking on "read eletters" on our homepage.

The editors will decide as before whether to also publish it in a future paper issue.

\section{Perceptions of mosquito borne diseases}

We report our findings from a community based study on Knowledge Attitude Practice of community on various vector (mosquito) borne diseases, conducted in 1998. The re spondents $(n=850)$ in a sample (systematic random) were chosen from the population of 10000 of an urban locality in India. Knowledge of mosquito being the vector for dengue was very low $(0.5 \%)$, as compared with malaria $(61.1 \%)$. Concerning knowledge of breeding grounds for malaria mosquitoes; most identified drains $(48.6 \%)$ whereas only a few identified clean water or overhead tanks $(10.9 \%)$ as a potential breeding ground. The respondents were asked what they could do to reduce or eliminate mosquitoes. Most identified chemicals $(42.9 \%)$ while other respondents mentioned variety of measures like environmental hygiene, de-weeding, emptying containers, etc. The overwhelming majority of respondents $(56.8 \%)$ were of the attitude that mosquito control was the government's responsibility, very few $(8 \%)$ said that it was the responsibility of the people themselves. Widely used personal protection methods against mosquitoes were; repellents $(64 \%)$ and bed nets $(8.7 \%)$. Very few of the respondents $(1.1 \%)$ suggested mosquito proof screen/mesh for windows and doors of house.

Aedes aegeptii mosquito (vector for dengue) breed in small artificial collections of water like unused tyres, flower pot bases, broken bottles, etc. It is disappointing that more than $99 \%$ of respondents in our study did not know the mode of transmission for dengue, when in fact, community participation is the only effective way to prevent dengue outbreaks in the community. Behavioural theory suggests that people will be willing to put more effort into avoiding dengue if the consequences for not controlling mosquitoes seemed greater.

Anophelines species of mosquitoes (vector for malaria) breed mainly in clean water in contrast with the most widely held perception that they breed in drains or dirty water. Some of these misperceptions have been important hurdles affecting community participation in malaria control.

Our findings highlight the importance and need for intensification of health education for vector control, particularly in tropical countries, with emphasis on community participation to control vector borne diseases.

R Kumar, S K Krishnan, N Rajashree, R R Patil, T J Cauverappa, V Maiya Community Health Cell, no 367, Sreenivasa Nilaya, Jakkasandra 1st Main, 1 st Block, Koramangala, Bangalore-560034, India

Correspondence to: Dr R Patil rajanpatil@yahoo.com

Reference

1 Janz NK,Becker NH. The health belief model: a decade later. Health Educ $Q$

$1984 ; 11: 1-47$

\section{BOOK REVIEWS}

The health of nations: why inequality is harmful to your health?

I Kawachi, B P Kennedy. (Pp 220; \$25.95) New York: The New Press, 2002. ISBN 1-56584-582-X.

It was only six years ago that Richard $G$ Wilkinson published his path-breaking book Unhealthy societies. The afflictions of inequality, in which he argued that among developed countries it is not the richest societies that have the best health, but those that have the smallest income differences between rich and poor Wilkinson's pioneering ideas on the social and health consequences of inequality have clearly inspired the work of many health scientists and social policy analysts around the world ever since, including the work of Kawachi and Kennedy and their recent book, The health of nations.

In a skillfully crafted volume, the writers demonstrate how growing inequalities in the United States and elsewhere threaten various, highly valued freedoms that economic development and prosperity are supposed to bring about. Using examples mainly from the USA, the authors show chapter by chapter, the enormous social costs of growing economic inequalities and social injustices that continue to deny good health and adequate health care for many. Furthermore, inequalities continue to persist as obstacles to exercise democratic choice, undermine community and family life, and inspire those who are unable to attain the community standard of living to commit crime.

The health of the nations is an excellent book that deserves to be read by a broad readership and the authors are to be congratulated. The volume will hopefully serve as an important contribution to the ongoing public debate about the value of economic development that is unable to bring about social and distributive justice. The health of the nations is an essential and eye opening reading for everyone, especially for those, who still wrongly believe that inequality is the engine for growth, ensuring that the benefits automatically will trickle down to those at the bottom.
Piroska Östlin

Karolinska Institutet, Department of Public Health Sciences, Division of International Health, 17176 Stockholm, Sweden

\section{Continuous Morbidity Registration sentinel stations. The Netherlands 2000}

Edited by A I M Bartelds. (Pp 162; €15.) Utrecht: NIVEL, Netherlands Institute for health services research, 2002. ISBN 90-6905555-4.

The purpose of the book is to present data gathered by 67 general practitioners (GPs) in a national network of 47 sentinel stations covering $1 \%$ of the Dutch population. Sentinel GPs submit a weekly form to report certain illnesses, occurrences, and procedures. The book describes topic conditions for the "weekly returns", practice populations, methods, scale, and continuity of reporting. Appropriate feedback to those providing data is given though the audience targeted is not defined. Frequencies by sex, age group, season, province group, and degree of urbanisation are presented in clear figures and tables accompanied with summary text.

Seventy eight topics and 14 incidental studies have been presented since 1970. The weekly returns for 2000 include 14 topics and 3 incidental studies. Important findings on topics are: the mildest season with influenzalike illnesses since 1970; more new diabetes mellitus patients in rural areas; more urethritis in the male 65-74 year group; rise in "stomach flu" among 0-4 year olds; and GPs seem to perform less rectal touch examinations for prostate complaints, despite more GP requests for PSA tests no increase in suspected prostate cancer is observed.

In addition, the book shows Continuous Morbidity Registration (CMR) data on influenza and chickenpox collected for European projects, as well as 31 scientific reports, 38 papers in medical journals, and 3 dissertations mentioned or presented with abstracts.

Sentinel surveillance data are extremely useful in obtaining, reinforcing of increasing commitment of politicians, the health sector and other key sectors to observe trends and to respond with prevention and control programmes. The book presents CMR as one of the projects in which information is collected on a continuous basis on problems and diseases submitted to the GP and action taken by the GP, and is specifically of interest for primary healthcare research institutes and GPs involved in sentinel projects.

I R A L van Laere

Municipal Health Service, outreach primary care for the homeless, PO Box 2200, 1000 CE Amsterdam, Netherlands

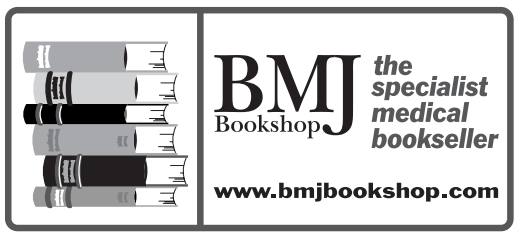

